Fanton, H. et.al. (2020). Pomphorhynchus laevis manipulates Gammarus pulex behaviour despite salt pollution. Freshwater Biology. 2020; 65: 1718-1725. https://doi.org/10.1111/fwb.13573

\title{
Pomphorhynchus laevis manipulates Gammarus pulex behaviour despite salt pollution
}

\author{
$\underline{\text { FANTON Hadrien }}{ }^{1}, \underline{\text { FRANQUET Evelyne }}{ }^{1}, \underline{\text { LOGEZ }}$ Maxime $^{2} \& \underline{\text { KALDONSKI }}$ \\ Nicolas ${ }^{1}$
}

Freshwater Biology. 2020; 65 : 1718-1725.

DOI: 10.1111/fwb.13573

https://onlinelibrary.wiley.com/doi/full/10.1111/fwb.13573

\footnotetext{
${ }^{1}$ Aix Marseille Univ, Avignon Université, CNRS, IRD, IMBE, Marseille, France.

${ }^{2}$ INRAE, Aix Marseille Université, RECOVER, Aix-en-Provence, France.
}

Author for correspondence: Hadrien Fanton, E-mail: hadrien.fanton@imbe.fr,

\section{Publication history}

Version of Record online:

23 June 2020

Manuscript accepted:

19 May 2020

Manuscript revised:

14 May 2020

Manuscript received:

15 October 2019

NB: This version of the manuscript corresponds to the last version before proof-editing by the journal. Some changes made by the editor afterwards may not be present in this version. See online article on the journal's website for the final version of the article. 
Fanton, H. et.al. (2020). Pomphorhynchus laevis manipulates Gammarus pulex behaviour despite salt pollution. Freshwater Biology. 2020; 65: 1718-1725. https://doi.org/10.1111/fwb.13573

\section{Abstract}

1. Salt pollution of freshwater ecosystems represents a major threat to biodiversity, and particularly to interactions between free-living species and their associated parasites. Acanthocephalan parasites are able to alter their intermediate host's phenotype to reach final hosts, but this process could be affected by salt pollution, thereby compromising survival of the parasite.

2. We experimentally assessed the impact of salt on the extended phenotype of the parasite Pomphorhynchus laevis in their intermediate host, the amphipod Gammarus pulex, based on three amphipod behaviours: distance covered in flowing water, phototaxis and geotaxis. We hypothesised that: (1) salt pollution negatively affected the behaviour of uninfected gammarids, and (2) that $P$. laevis could maintain their capacity to manipulate their host despite this pollution.

3. All three amphipod behaviours were altered by $P$. laevis: infected $G$. pulex covered a greater distance, were less photophobic and were more attracted to the water surface than uninfected amphipods, in control or salt-polluted water. However, salinity reduced distance covered in flowing water and increased attraction to the water surface of uninfected and infected $G$. pulex. For the phototaxis behaviour, $P$. laevis enhanced this capacity of manipulation in salt-polluted water compared to control water.

4. Pomphorhynchus laevis can still manipulate the behaviour of their intermediate host in saltpolluted water. Acanthocephalan parasites have not been known to be able to manipulate their intermediate host when under pollution stress. Trophic interactions, but not the chances of parasite transmission to their definitive host, appear to be affected by salt pollution.

5. Our study indicates that behavioural modifications induced by complex lifecycle parasites should be more considered in the context of growing concentrations of chemical pollutants in some freshwater ecosystems. Interspecific interactions, and particularly host-parasite relationships, are a key component of ecosystems stability and their alteration could result in major changes in energy flow.

Keywords: Salinisation, acanthocephala, amphipoda, host-parasite interactions, phenotypic alterations

\section{Introduction}

Increased salinity constitutes one of the major stresses for freshwater organisms, affecting their biology and their ecology (Canedo-Arguelles et al., 2013; Velasco et al., 2018). Ionic concentration can naturally vary in freshwater environments, due for example to seasonal cycles, geological substrates or rainfalls (Herczeg, Doramaci, \& Leaney, 2001). However, recent pronounced secondary salinisation from anthropogenic sources is extending the salinity range in some freshwater ecosystems, already considered among the most endangered and vulnerable (Malmqvist \& Rundle, 2002). Road salt accumulation, water management and industrial pollution have harmful effects on freshwater ecosystems (Marcogliese, 2008; Kaushal et al., 2018). Continuous exposure to these multiple pressures, combined with factors like climate change, are altering the productivity, composition and distribution of freshwater species and are 
Fanton, H. et.al. (2020). Pomphorhynchus laevis manipulates Gammarus pulex behaviour despite salt pollution. Freshwater Biology. 2020; 65: 1718-1725. https://doi.org/10.1111/fwb.13573

affecting energy flows in freshwater ecosystems (Dunn \& Hatcher, 1997; Herbert et al., 2015; Piscart, Lecerf, Usseglio-Polatera, Moreteau, \& Beisel, 2005). River salinity will, moreover, probably continue to increase due to increasing water temperature, and thus water evaporation, induced by climate change (Hengeveld, 1990; Arnell \& Reynard, 1996; Sereda, Bogard, Hudson, Helps, \& Dessouki, 2011).

Despite evidence of numerous impacts of salt pollution in a wide range of ecological and geographical contexts, how it affects interactions between free-living organisms and associated parasites remains unclear (Piscart, Moreteau, \& Beisel, 2005; Castillo et al., 2018). This applies particularly to acanthocephalan complex lifecycle parasites (CLP), which generally rely on 2 hosts to complete their lifecycle: an arthropod intermediate host eating free parasite eggs that will hatch and mature within it, and a final vertebrate host in which parasites will reproduce, laying their eggs in the host's intestine and thus ensuring their release. As parasite transmission generally depends on the final host eating the intermediate host, acanthocephalan CLP are able to alter the behaviour of their intermediate host to enhance this trophic link. These behavioural changes are adaptive and induce greater vulnerability to a definitive host predator (Bakker, Frommen, \& Thunken, 2017).

Many behavioural alterations in gammarid intermediate hosts are known to be induced by acanthocephalans (Cézilly, Grégoire, \& Bertin, 2013). Predation by definitive hosts increases because acanthocephalan-infected gammarids become more photophilous (Perrot-Minnot, Maddaleno, Balourdet, \& Cézilly, 2012; Kaldonski, Perrot-Minnot, \& Cézilly, 2007), reverse their geotaxis behaviour (Bauer, Haine, Perrot-Minnot, \& Rigaud, 2005), increase their activity (Maynard, Wellnitz, Zanini, Wright, \& Dezfuli, 1998), and have a higher drift rate (Lagrue, Kaldonski, Perrot-Minnot, Motreuil, \& Bollache, 2007). Such effects mediated by acanthocephalans shape and modify the structure of freshwater ecosystems (Lefèvre et al., 2009; Lafferty 1997; Hudson, Dobson, \& Lafferty, 2006).

Gammarid species are very tolerant to harsh environmental conditions and have osmoregulatory mechanisms that allow them to withstand hyperionic environments (Hoback \& Barnhart, 1996; Piscart, Webb, \& Beisel, 2007; Wijnhoven, van Riel, \& van der Velde, 2003; Brooks \& Mills, 2011). For example, the $\mathrm{LC}_{50}$ of Gammarus pulex was reach for a salinity concentration of 12.8g/L (Piscart, Kefford, \& Beisel, 2011). Despite their tolerance, freshwater gammarids are stenohaline species and are more sensitive to high salinity than estuarine species or marine species (Sutcliffe, Carrick, \& Willoughby, 1981). Under extreme salinity, another freshwater gammarid, Gammarus fossarum, was reported to strongly defecate, to starve and to show a sharp decline in survival rate (Dorgelo, 1974). Survival, ventilation, locomotion, and hemolymph ionic concentrations in $G$. roeseli were also impaired by salinity stress (Sornom et al., 2010). These deleterious physiological effects could undoubtably affect the gammarids swimming or foraging behaviours, potentially including effects on their associated parasites (Piscart, Webb, \& Beisel, 2007, Xue et al., 2013). Piscart, Webb, \& Beisel, (2007) showed that acanthocephalan-infected gammarids were more tolerant to salinity, with a higher mean lethal salt concentration for infected than for uninfected individuals. Other studies by Labaude et al. (2017a) and Sanchez-Thirion et al. (2019) showed that Pomphorhynchus laevis still manipulate Gammarus pulex despite temperature or food changes, suggesting that acanthocephalan manipulation may occur even under environmental stress.

The aim of this study was to assess the effect of heavily salt-polluted water on three G. pulex behavioural alterations induced by $P$. laevis infection. In a controlled laboratory experiment, we 
Fanton, H. et.al. (2020). Pomphorhynchus laevis manipulates Gammarus pulex behaviour despite salt pollution. Freshwater Biology. 2020; 65: 1718-1725. https://doi.org/10.1111/fwb.13573

compared distance covered in flowing water, phototaxis and geotaxis of infected and uninfected $G$. pulex to assess the potential for $P$. laevis behavioural manipulation in highly saline polluted environments. Firstly, we hypothesised that the deleterious effect of salt pollution negatively affected the behaviour of uninfected gammarids. Secondly, we hypothesised that P. laevis maintain their capacity to manipulate their host even under the stress of salt pollution.

\section{Methods}

\section{Sampling and maintenance}

Behavioural experiments used naturally infected gammarids collected between April and June 2017 in the Arc River (Bouches-du-Rhône, Southern France, 43²8'18.2"N, 5³7'03.5"E / $\left.43^{\circ} 28^{\prime} 47.5^{\prime \prime N} 5^{\circ} 25^{\prime} 22.0^{\prime \prime E} / 3^{\circ} 47^{\prime} 22.1^{\prime \prime N}, 5^{\circ} 617^{\prime} 42.6^{\prime \prime E}\right)$. Gammarus pulex were sampled with a hand net in gravel, roots and aquatic vegetation along riverbanks regardless of their parasitic status but excluding juveniles ( $<4 \mathrm{~mm}$ (Blockwell, Pascoe, \& Taylor, 1996)). During the sampling period, the water temperature of the Arc River ranged between $14.7^{\circ} \mathrm{C}$ and $19.3^{\circ} \mathrm{C}$ and conductivity ranged between 869 and $977 \mu \mathrm{S} / \mathrm{cm}$.

Sampled G. pulex were placed in six $21 \mathrm{~L}$ aquaria $(60 \times 35 \times 10 \mathrm{~cm})$ equipped with oxygen bubblers, with a water height of $6-8 \mathrm{~cm}$ and $3 \mathrm{~mm}$ of substrate (fine gravel previously washed) for an acclimatisation period of 7 days. Laboratory temperature was controlled and maintained at $15^{\circ} \mathrm{C}$. Tap water used for acclimatisation and experiments was aerated with oxygen, and maintained at $15^{\circ} \mathrm{C}$. This temperature was chosen in accordance with the natural temperature regime of the Arc River during the sampling period and to avoid thermic stress. A neon light recreated $95 \%$ of the quality of the natural light spectrum $\left(5200^{\circ} \mathrm{K}, 400-600 \mathrm{Lux}\right)$ on a cycle of $12 \mathrm{~h} / 12 \mathrm{~h}$ light and dark regimes.

Acclimatised G. pulex individuals were placed in one of two 96L aquaria $(80 \times 30 \times 40 \mathrm{~cm})$ for 2 days. The first $96 \mathrm{~L}$ aquarium served as control and no treatment was added. In the second 96L aquarium, the effect of salt pollution was simulated by applying a salinity treatment: $6 \mathrm{~g} / \mathrm{L}$ of Sodium Chloride ( $\mathrm{NaCl}$, AnalaR Normapur ${ }^{\circledR}$, Radnor, Pennsylvania, U.S.A.) were dissolved in water, which corresponded to a conductivity of $8 \mathrm{mS} / \mathrm{cm}$. To anticipate behavioural experiments, gammarids were visually sorted in each aquarium, as potentially infected or not (depending on whether the acanthocephalan was visible through their translucid cuticle). During these two acclimatisation periods, no more than 100 gammarid individuals were placed in each aquarium to avoid competition, and individuals were fed ad libitum with leaves and shrimp food to avoid cannibalism.

After this second acclimatisation phase in the 96L aquarium, gammarids were randomly taken from the two 96L aquaria and the effects of parasite and salt on three different behaviours were assessed: distance covered in flowing water, phototaxis and geotaxis. Gammarids individuals were used for only one behavioural observation. Over the course of behavioural experiments, 467 G. pulex were studied. 
Fanton, H. et.al. (2020). Pomphorhynchus laevis manipulates Gammarus pulex behaviour despite salt pollution. Freshwater Biology. 2020; 65: 1718-1725. https://doi.org/10.1111/fwb.13573

\section{Behavioural experiments}

\section{Distance covered in flowing water}

Distance covered in flowing water was assessed in two artificial streams (Figure 1) of either control or saline water. Each artificial stream consisted of a graduated PVC gutter measuring $100 \times 17 \times 10 \mathrm{~cm}$ with a slope of $0.9^{\circ}$ and divided into seven sections of $10 \mathrm{~cm}$ each. A net $(1 \mathrm{~mm}$ mesh) used as a substrate for gammarids at the bottom of the artificial stream ran along its whole length and allowed individuals to cling against the water flow. A water pump placed in a 30L tank beside the artificial stream created a constant flow of water. Gammarids could thus swim and cling in or against a continuous flow replicating a slow current $(5 \mathrm{~cm} / \mathrm{s})$. On each day of experiments, one artificial stream was randomly selected for salinity treatment $(6 \mathrm{~g} / \mathrm{L} \mathrm{of} \mathrm{NaCl})$ and the other as control $(\approx 0 \mathrm{~g} / \mathrm{L} \mathrm{NaCl})$, and both were carefully cleaned at the each day's end. A total of 115 observations of distance covered by G. pulex were integrated for statistical analysis (Table 1).

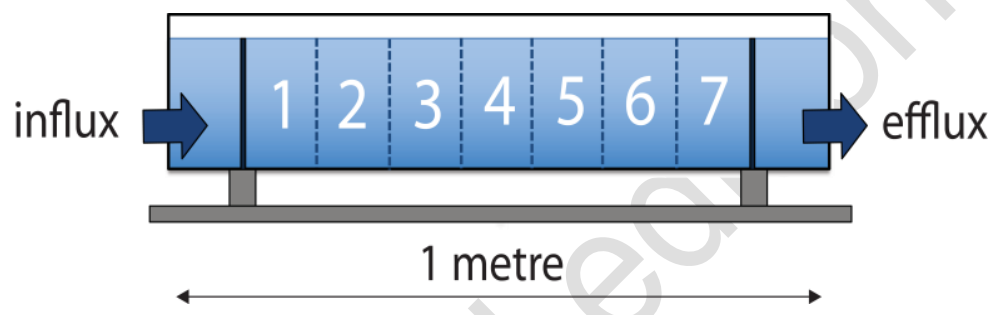

Figure 1. Illustration of the artificial stream $(100 \times 17 \times 10 \mathrm{~cm})$ used for distance covered experiments. Gammarids were observed in a 7-sections device (sections length $=10 \mathrm{~cm}$, numbered 1 to 7 ). Blue arrows indicate flow direction. A grid was used to isolate individuals in section "1" of the device for five minutes. The artificial stream was supplied with fresh water via a pump placed in a $30 \mathrm{~L}$ tank and creating a constant flow $(5 \mathrm{~cm} / \mathrm{s})$.

For each observation, one $G$. pulex individual was randomly selected from the $96 \mathrm{~L}$ aquariums and acclimatised for $5 \mathrm{~min}$ in section "1" of the artificial stream, using a removal grid. Isolation in section "1" ensured that there was minimum disturbance to individuals: with only one grid to manipulate, vibrations were limited. The grid was then removed, marking t0 of the behavioural observations. The gammarid's position in each section was continuously recorded for 5 min. Distance covered was determined by the number of sections crossed. For example, if a $G$. pulex individual was observed successively in sections 1-2-3-2-3-4-5-6 over 5min, it was considered to have crossed seven sections in the device. This number was multiplied by ten ( section length $=10 \mathrm{~cm}$ ) to obtain the distance covered in centimetres (in the example above: distance covered $=70 \mathrm{~cm}$ ).

Table 1. Number and status of gammarids studied for each behaviour (total) and for each level of treatment.

\begin{tabular}{|l|c|c|c|c|c|}
\hline Treatment & \multicolumn{2}{|c|}{ Control water } & \multicolumn{2}{c|}{ Saline water } & \\
\hline Parasitic status & Uninfected & Infected & Uninfected & Infected & Total \\
\hline Distance covered & 29 & 21 & 37 & 28 & 115 \\
\hline Phototaxis & 52 & 33 & 61 & 32 & 178 \\
\hline Geotaxis & 39 & 40 & 62 & 33 & 174 \\
\hline
\end{tabular}


Fanton, H. et.al. (2020). Pomphorhynchus laevis manipulates Gammarus pulex behaviour despite salt pollution. Freshwater Biology. 2020; 65: 1718-1725. https://doi.org/10.1111/fwb.13573

\section{Phototaxis}

Phototaxis, the response (attraction or repulsion) to a light stimulus, was assessed using a protocol adapted from Perrot-Minnot (2004). One acclimatised gammarid was placed in a small plastic aquarium $(35 \times 9 \times 8 \mathrm{~cm})$ filled with $1.2 \mathrm{~L}$ of either control water or saline water, which corresponds to a water depth of $4 \mathrm{~cm}$. Half of the plastic aquarium was covered with a black PVC plate to achieve a fully «dark section» and the other half, or «light section», was illuminated $\left(5200^{\circ} \mathrm{K}, 400-600 \mathrm{Lux}\right)$. Every experimental day, five plastic aquaria were selected for salinity treatment $(6 \mathrm{~g} / \mathrm{L}$ of $\mathrm{NaCl})$ and five plastic aquaria were used as control $(\approx 0 \mathrm{~g} / \mathrm{L} \mathrm{NaCl})$. After $5 \mathrm{~min}$ of acclimatisation in the device, the position of the gammarid was recorded every $30 \mathrm{sec}$ for $5 \mathrm{~min}$. Two positions were recorded and scored as 0 (gammarid in dark section) or 1 (gammarid in light section). For each individual, summed phototaxis scores after observations ranged from 0 (always in dark section) to 10 (always in light section). After each observation, the water was removed, and the plastic aquaria were cleaned and refilled before observing the next individual. A total of 178 observations of $G$. pulex phototaxis behaviour were used for the statistical analyses (Table $1)$.

\section{Geotaxis}

Geotaxis, or the response of individuals to gravity, was estimated as the average vertical position of individuals in the water column. To assess geotaxis, we used a method similar to Cézilly et al. (2000), filling a 500mL graduated translucent column (diameter $=5 \mathrm{~cm}$ ) with either control or saline water. Columns were virtually subdivided into 5 sections $(1$ section $=100 \mathrm{~mL}$ of water), from section " 1 " closest to the bottom to section " 5 " closest to the water surface. A small strip of netting allowed gammarids to cling inside the device. Every experimental day, 5 columns were selected for salinity treatment $(6 \mathrm{~g} / \mathrm{L}$ of NaCl$)$ and five columns were used as control $(\approx 0 \mathrm{~g} / \mathrm{L}$ $\mathrm{NaCl}$ ). One gammarid was randomly selected from the $96 \mathrm{~L}$ aquaria and acclimatised in the column for $5 \mathrm{~min}$. After these 5 minutes of acclimatisation, their geotaxis behaviour was observed for $5 \mathrm{~min}$, with their position recorded every 30sec. and scored 1 to 5 according to section. For each observed gammarid, summed geotaxis scores ranged from 10 (always at the bottom of the column) to 50 (always at the top of the column). After each behavioural observation, the water was removed and the device was cleaned and refilled for the next observation. A total of 174 observations of $G$. pulex geotaxis behaviour were incorporated in the statistical analyses (Table $1)$.

\section{Dissection and parasite identification}

After behavioural observations, gammarids were individually stored in ethanol $(96 \%)$ before dissection and parasite identification. Individuals were measured (length of the fourth coxal plate, Bollache \& Cézilly, 2000) and sexed (morphology of the second pair of gnathopods, Hume et al., 2005) with a SMZ1500 Nikon stereomicroscope (Mitsubishi, Tokyo, Japan) coupled with an R1 Nikon camera (Mitsubishi, Tokyo, Japan) connected to a computer with NIS-Br software. Gammarus pulex individuals were dissected to attest acanthocephalan infection, identify parasite species, and count the number of parasites. Phenotypic alteration induced by acanthocephalans on their intermediate hosts depends on both species and developmental stage of the parasite. Therefore, a posteriori exclusion-inclusion of gammarids was applied after dissection, and only cystacanth stages (i.e. infective stage) of $P$. laevis were considered, while 
Fanton, H. et.al. (2020). Pomphorhynchus laevis manipulates Gammarus pulex behaviour despite salt pollution. Freshwater Biology. 2020; 65: 1718-1725. https://doi.org/10.1111/fwb.13573

acanthella stages (i.e. non-infective stage) were not included in analyses. Developmental stages and species of parasites were determined based on morphological identification following PerrotMinnot (2004).

\section{Data analysis}

Heterogeneity in the number of gammarids observed for each behaviour (Table 1) was due to blindfold observations, leading to a posteriori exclusion-inclusion of individuals after dissection. Gammarid body size did not differ significantly between uninfected and P. laevisinfected gammarids used for behavioural observations (Mann-Whitney test: W=3619, $P=0.838$ ). Sex did not affect gammarid behaviour in terms of distance covered (Mann-Whitney test: $\mathrm{W}=1361.5, P=0.107$ ), phototaxis (Mann-Whitney test: $\mathrm{W}=3578.5, P=0.386$ ), or geotaxis (Mann-Whitney test: $\mathrm{W}=3385, P=0.431$ ). Gammarid size and sex were therefore not considered further in the statistical analyses. Too few $G$. pulex were infected by more than one $P$. laevis and this did not allow statistical analysis to compare the effect of different parasite load.

Two-way fixed factor ANOVAs were performed to determine the effects of P. laevisinfection (two levels: with or without parasites), salinity (two levels: 0 and $6 \mathrm{~g} / \mathrm{L}$ ) and their interaction, on the three behavioural variables (distance covered, phototaxis and geotaxis). For distance covered and geotaxis, residual diagnostics indicated that the normality assumption for linear models was met, but the homogeneity of variances (heteroscedasticity) assumption was not met. Generalised least squares (GLS) was thus used to extend the linear model by modelling the heterogeneity with covariates (Zuur, Ieno, Walker, Saveliev, \& Smith, 2009). The interaction between $P$. laevis-infection and salinity was not significant ( $F$-tests, all $p$-values $>0.05)$. Therefore, we considered only the additive effects (without interaction) of salinity and P. laevisinfection. Statistical analyses were conducted using R 3.5.0 software (A Language and Environment for Statistical Computing), and the additional libraries "nlme" (Pinheiro, Bates, Debroy, \& Sarkar, 2019), "AICmodavg" (Mazerolle, 2019), "ggplot2" (Wickham, 2016) and "car" (Fox \& Weisberg, 2018).

\section{Results}

\section{Distance covered in flowing water}

Pomphorhynchus laevis-infected gammarids covered a greater distance than uninfected gammarids $\left(\mathrm{F}_{1,112}=24.088, P<0.001\right.$, Table $\left.\mathrm{S} 1\right)$, as revealed by their higher expected values (Figure 2). Salt pollution significantly decreased distance covered by the gammarids regardless of their infection status $\left(\mathrm{F}_{1,112}=7.057, P<0.01\right.$, Table $\left.\mathrm{S} 1\right)$, as no significant interaction was found (Table S1). Pomphorhynchus laevis infection led to host manipulation and greater distance covered regardless of salinity concentration. 
Fanton, H. et.al. (2020). Pomphorhynchus laevis manipulates Gammarus pulex behaviour despite salt pollution. Freshwater Biology. 2020; 65: 1718-1725. https://doi.org/10.1111/fwb.13573

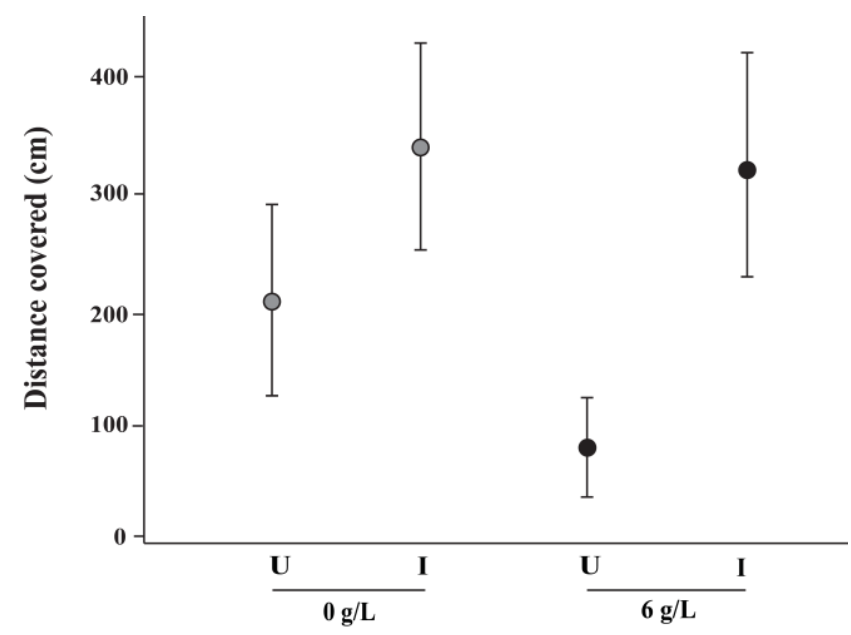

Figure 2. The expected values (dots) of the distance covered by gammarids under each treatment (combination of infected status and salinity), and their confidence interval (95\%, lines). (U) represent uninfected G. pulex and (I) P. laevis-infected G. pulex at the salinity tested (0g/L and $6 \mathrm{~g} / \mathrm{L})$. Effects of infection, and salinity are given in Table $\mathrm{S} 1$.

\section{Phototaxis}

An interaction effect was found between infection status and saline treatment $\left(\mathrm{F}_{1,174}=5.924, P<0.05\right.$, Table $\left.\mathrm{S} 1\right)$. Infected gammarids were always highly photophilous whatever the salinity, while uninfected gammarids were less photophilous and their photophobia even increased with salinity (Figure 3). This results in a greater deviation between uninfected and infected gammarids along saline gradient (Figure 3).

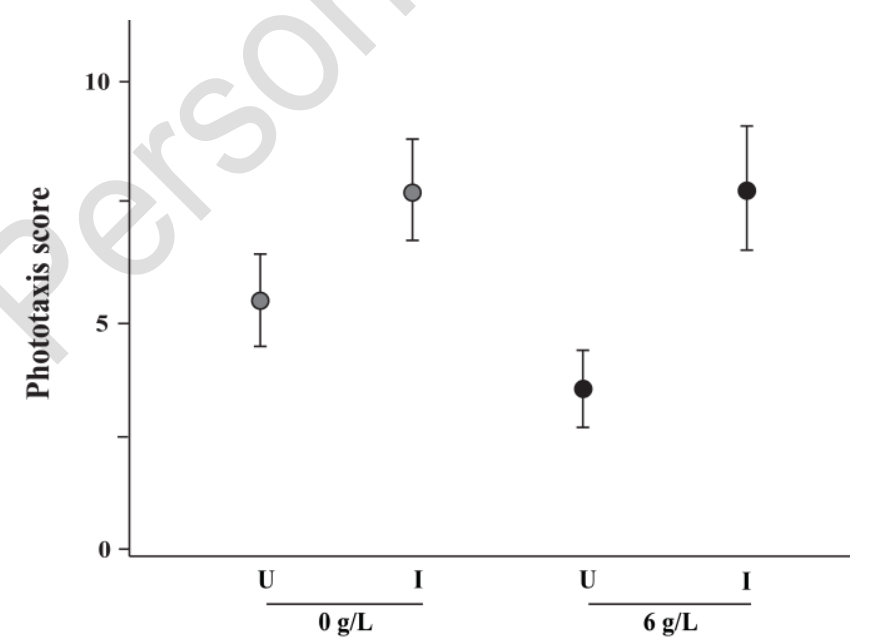

Figure 3. The expected values (dots) of the phototaxis score of gammarids under each treatment (combination of infected status and salinity), and their confidence interval (95\%, lines). (U) represent uninfected G. pulex and (I) P. laevis-infected G. pulex at the salinity tested (0g/L and $6 \mathrm{~g} / \mathrm{L})$. Effects of infection, salinity and their interaction are given in Table S1. 
Fanton, H. et.al. (2020). Pomphorhynchus laevis manipulates Gammarus pulex behaviour despite salt pollution. Freshwater Biology. 2020; 65: 1718-1725. https://doi.org/10.1111/fwb.13573

\section{Geotaxis}

Infected gammarids were more attracted to the water surface than uninfected gammarids $\left(\mathrm{F}_{1,171}=29.896, P<0.001\right.$, Table $\left.\mathrm{S} 1\right)$, displaying higher expected geotaxis score (Figure 4). Salinity treatment significantly increased water surface attraction for gammarids regardless of their infection status $\left(\mathrm{F}_{1,171}=5.222, P<0.05\right.$, Table $\left.\mathrm{S} 1\right)$, as the interaction between salinity and infection was not significant (Table S1). Regardless of this effect, $P$. laevis-infection still led to host manipulation and increased water surface attraction.

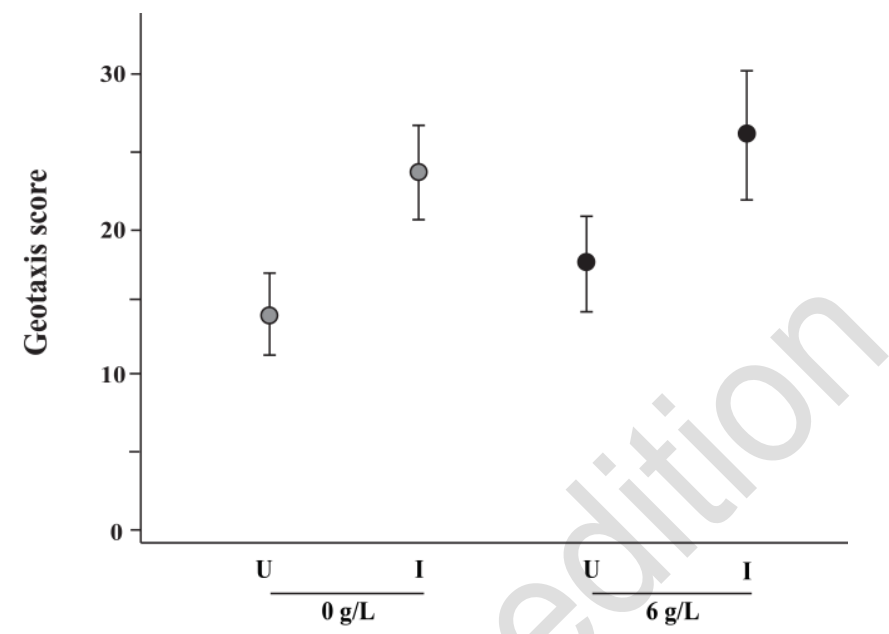

Figure 4. The expected values (dots) of the geotaxis score of gammarids under each treatment (combination of infected status and salinity), and their confidence interval (95\%, lines). (U) represent uninfected G. pulex and (I) P. laevis-infected G. pulex at the salinity tested (0g/L and $6 \mathrm{~g} / \mathrm{L})$. Effects of infection, and salinity are given in Table $\mathrm{S} 1$.

\section{Discussion}

Pomphorhynchus laevis-infected G. pulex covered a greater distance in flowing water, were more attracted to light, and were more attracted to the water surface than uninfected $G$. pulex, thereby increasing their risk of predation by fish, which are the parasite's definitive host. Firstly, $P$. laevis induced their hosts to move more and to cover a greater distance in or against the water flow in the artificial river. Secondly, $P$. laevis increased their host's attraction to light and to the water surface, behaviours that could reduce the time hosts spend hidden in a shelter. All these behaviours make $P$. laevis-infected gammarids easy prey for freshwater predators. In running waters, the definitive hosts of P. laevis, like chub (S. cephalus) or trout (Salmo trutta) are visual predator in the water column feeding on drifting invertebrates. Enhanced geotaxis could increase the time gammarids spent in the drift, increasing the risk of being preyed upon and thereby also the chances of the parasite completing its lifecycle. These results agree with other studies proving that acanthocephalan CLP induce greater drift (Lagrue, Kaldonski, PerrotMinnot, Motreuil, \& Bollache, 2007; McCahon, Maund, \& Poulton, 1991; Zganec, Gottsein, \& Hudina, 2013) and greater swimming activity (Dezfuli, Maynard, \& Wellnitz, 2003), decrease photophobia (Bauer, Trouvé, Grégoire, Bollache, \& Cézilly, 2000; Kaldonski, Perrot-Minnot, Dodet, Martinaud, \& Cézilly, 2009) and enhance geotaxis (Perrot-Minnot, Sanchez-Thirion, \& Cézilly, 2014; Médoc, Bollache, \& Beisel, 2006) in their intermediate host. To enhance its own transmission rate, $P$. laevis is able to completely modify $G$. pulex behaviours in flowing water. 
Fanton, H. et.al. (2020). Pomphorhynchus laevis manipulates Gammarus pulex behaviour despite salt pollution. Freshwater Biology. 2020; 65: 1718-1725. https://doi.org/10.1111/fwb.13573

Salinity significantly reduced the distance covered in the stream and increased the geotaxis score of both uninfected and $P$. laevis-infected gammarids. Moreover, uninfected gammarids were more photophobic in saline water than in control water. The attraction towards the water surface observed during the geotaxis experiment, could be due to hyperventilation and an increased need for oxygen caused by osmotic stress. Thus, salt pollution affected not only the physiology of $G$. pulex but also their overall behaviour in the stream.

Pomphorhynchus laevis retained its ability to manipulate the behaviour of G. pulex under salt pollution, with an increased effect on their phototaxis behaviour. This may preserve the capacity for parasite transmission between the intermediate and definitive host despite a heavily saltpolluted environment. These results agree with the findings of Piscart et al. (2007), whose experiments showed that infection by the acanthocephalan Polymorphus minutus increased the salinity tolerance of $G$. roeseli. Polymorphus minutus-infected gammarids had a mean lethal salt concentration for $50 \%$ mortality $\left(\mathrm{LC}_{50}\right)$ of $17.3 \mathrm{~g} / \mathrm{L}$, whereas the $\mathrm{LC}_{50}$ of uninfected gammarids was $9.7 \mathrm{~g} / \mathrm{L}$ (Piscart, Webb, \& Beisel, 2007). Similarly, Labaude et al. (2017a) and SanchezThirion et al. (2019), showed that P. laevis still manipulated the behaviour of G. pulex despite temperature stress or poor-quality food resources, respectively. Compared to their gammarid intermediate hosts, acanthocephalans are able to accumulate very large concentrations of chemical pollutants (Paller, Resurreccion, de la Cruz, \& Bandal, 2016; Sures, Taraschewski, \& Jackwerth, 1994; Sures, Sidall, \& Taraschewski, 1999). The capacity of parasites to accumulate substantial pollutant concentrations has been shown to decrease concentrations in their host's body, allowing the host to escape critical damage (Brown \& Pascoe, 1989; Paller, Resurreccion, de la Cruz, \& Bandal, 2016; Sanchez et al., 2016). Although salinity impacted the phototaxis behaviour of uninfected gammarids, $P$. laevis-infected gammarids were not affected by the saline treatment and showed the same phototaxis behaviour as those in control water.

According to Piscart et al. (2007), the heightened tolerance of infected gammarids could be due to the capacity of acanthocephalan parasites to induce physiological changes in their host. These include reduced $\mathrm{O}_{2}$ consumption, increased hemocyanin concentration and changes in hemocoel or hemolymph concentrations of solutes and proteins, which could improve the host's chances of survival in a hypersaline environment. In another study, at a salinity of $6 \mathrm{~g} / \mathrm{L}$, the presence of cystacanth in a $G$. pulex haemocoel reduced the volume available and decreased sodium influx and efflux, thereby disturbing the gammarid's sodium regulation (Brooks \& Mills, 2011). Environmental stress has been shown to modulate the immune system of gammarids (Le Moullac \& Haffner, 2000; Labaude, Moret, Cézilly, Reuland, \& Rigaud, 2017b). According to Le Moullac \& Haffner (2000), changes in environmental factors can lead to stress-induced immunosuppression in crustacean species. Pomphorhynchus laevis may take advantage of environmental shifts like pollution if gammarids increase the resources allocated to salt resistance at the expense of parasite resistance. On the other hand, salinity may be deleterious to acanthocephalan parasites, having as yet unknown effects on their physiology or different lifecycle stages. Although acanthocephalan parasites are able to accumulate pollutants, the effect of salinity on acanthocephalan eggs is unknown (Sures, Taraschewski, \& Jackwerth, 1994). Acanthor eggs are directly in contact with water, and chronic salt pollution may impact their protective envelope. Another possible deleterious effect concerns transmission of acanthor eggs to gammarids. A study on gammarid microsporidian parasites showed that the parasite burden was significantly greater at control salinity than at high salinity (Dunn \& Hatcher, 1997), with a lower proportion of the young infected in broods from water of elevated salinity (Dunn \& 
Fanton, H. et.al. (2020). Pomphorhynchus laevis manipulates Gammarus pulex behaviour despite salt pollution. Freshwater Biology. 2020; 65: 1718-1725. https://doi.org/10.1111/fwb.13573

Hatcher, 1997). Moreover, heavy salt pollution drastically reduces gammarid feeding (Dorgelo, 1974), and this could lower the acanthocephalan egg infection rate due to ingestion.

Salt pollution of freshwater ecosystems will be accentuated by climate change and anthropic pollution in many rivers (Williams, 2001; Canedo-Arguelles et al., 2013; Castillo et al., 2018; Kaushal et al., 2018). This increases the risk of severe biodiversity losses and could compromise trophic links in freshwater ecosystems (Castillo et al., 2018). One current challenge is to better understand the influence of salinisation on freshwater host-parasite complexes and on entire ecosystems (Williams, 2001; Herbert et al., 2015; Castillo et al., 2018; Kaushal et al., 2018). Increased salinisation of freshwater environments will undeniably affect freshwater CLP and their hosts by impacting their life cycles and transmission, but also indirectly through the biology of their hosts (Marcogliese, 2008). In this study, both uninfected and infected gammarids were affected by heavy saline pollution, which reduced their distance covered and increased their attraction to the water surface. These behavioural alterations are bound to have consequences in natura, leading to modifications of intra/interspecific interactions and shifts in ecosystem composition. According to Herbert et al. (2015), existing interspecific interactions are very likely to be disturbed by salt pollution. Here, in fact, uninfected gammarids showed sharply decreased activity in flowing water and greater photophobia in the saline treatment. This would reduce their capacity to prospect for food or partners, and their availability as a food resource for freshwater predators.

Interestingly, our experimental observations showed that $P$. laevis is able to manipulate the behaviour of its intermediate host even in a heavily polluted environment. This capacity for transmission allows acanthocephalan parasites to reach their definitive fish hosts even in a saltpolluted environment, thus maintaining interspecific interactions between intermediate and definitive acanthocephalan hosts. Better understanding of how salinity alters free-living hosts and their CLP composition and interaction represents a major challenge for predicting future changes in freshwater biodiversity (Castillo et al., 2018). Further experimental studies should investigate the negative impacts of salinisation on gammarid invertebrates. It would also be valuable to further explore the extent to which acanthocephalan parasites can continue to achieve transmission to definitive hosts despite growing concentrations of salt and other chemical pollutants in freshwater ecosystems. 
Fanton, H. et.al. (2020). Pomphorhynchus laevis manipulates Gammarus pulex behaviour despite salt pollution. Freshwater Biology. 2020; 65: 1718-1725. https://doi.org/10.1111/fwb.13573

\section{Acknowledgements}

We are grateful to Coralie Jacquemin, Eric Meineri and Maxine Thorel for their comments and suggestions that helped improve an earlier version of the manuscript. We thank Mathilde Gaston for her excellent work and help with behavioural observations. Finally, we thank Marjorie Sweetko for improving the English of this manuscript.

This work was funded by the Labex DRIIHM, French programme "Investissements d'Avenir" (ANR-11-LABX-0010) managed by the ANR within the Observatoire HommesMilieux Bassin Minier de Provence (OHM BMP) and the ECCOREV Research Federation (FR 3098). Hadrien Fanton received a PhD fellowship from the Ministère de la Recherche et de l'Enseignement Supérieur and this paper is part of his Ph.D. thesis.

\section{Data availability statement}

Data available on request from the authors

\section{Conflict of interest}

None of the authors declare any conflict of interest. 
Fanton, H. et.al. (2020). Pomphorhynchus laevis manipulates Gammarus pulex behaviour despite salt pollution. Freshwater Biology. 2020; 65: 1718-1725. https://doi.org/10.1111/fwb.13573

\section{References}

Arnell, N. W., \& Reynard, N. S. (1996). The effects of climate change due to global warming on river flows in Great Britain. Journal of Hydrology, 183(3-4), 397-424.

Bakker, T. C. M., Frommen, J. G., \& Thunken, T. (2017). Adaptive parasitic manipulation as exemplified by acanthocephalans. Ethology, 123(11), 779-784. doi:10.1111/eth.12660

Bauer, A., Trouvé, S., Grégoire, A., Bollache, L., \& Cézilly, F. (2000). Differential influence of Pomphorhynchus laevis (Acanthocephala) on the behaviour of native and invader gammarid species. International Journal for Parasitology, 30(14), 1453-1457. doi:10.1016/s0020-7519(00)00138-7

Bauer, A., Haine, E. R., Perrot-Minnot, M.-J., \& Rigaud, T. (2005). The acanthocephalan parasite Polymorphus minutus alters the geotactic and clinging behaviours of two sympatric amphipod hosts: the native Gammarus pulex and the invasive Gammarus roeseli. Journal of Zoology, 267, 39-43. doi:10.1017/s0952836905007223

Beermann, A. J., Elbrecht, V., Karnatz, S., Ma, L., Matthaei, C. D., Piggott, J. J., \& Leese, F. (2018). Multiple-stressor effects on stream macroinvertebrate communities: a mesocosm experiment manipulating salinity, fine sediment and flow velocity. Science of the Total Environment, 610, 961-971. doi: 10.1016/j.scitotenv.2017.08.084

Blockwell, S. J., Pascoe, D., \& Taylor, E. J. (1996). Effects of lindane on the growth of the freshwater amphipod Gammarus pulex (L.). Chemosphere, 32(9), 1795-1803. doi: 10.1016/0045-6535(96)00111-7

Bollache, L., \& Cézilly, F. (2000). The influence of micro-habitat segregation on size assortative pairing in Gammarus pulex (L.) (Crustacea, Amphipoda). Archiv für Hydrobiologie, 547558. doi: 10.1127/archiv-hydrobiol/147/2000/547

Boyce, N. P., \& Yamada, S. B. (1977). Effects of a parasite, Eubothrium salvelini (Cestoda Pseudophyllidea), on resistance of juvenile sockeye salmon, Oncorhynchus nerka, to zinc. Journal of the Fisheries Research Board of Canada, 34(5), 706-709.

Brooks, S. J., \& Mills, C. L. (2011). Parasitic infection manipulates sodium regulation in the freshwater amphipod Gammarus pulex (L.). Comparative Biochemistry and Physiology aMolecular \& Integrative Physiology, 159(3), 247-252. doi:10.1016/j.cbpa.2011.03.011

Brown, A. F., \& Pascoe, D. (1989). Parasitism and host sensitivity to cadmium - An Acanthocephalan infection of the freshwater Amphipod Gammarus pulex. Journal of Applied Ecology, 26(2), 473-487. doi:10.2307/2404075

Canedo-Arguelles, M., Kefford, B. J., Piscart, C., Prat, N., Schafer, R. B., \& Schulz, C. J. (2013). Salinisation of rivers: An urgent ecological issue. Environmental Pollution, 173, 157-167. doi:10.1016/j.envpol.2012.10.011

Castillo, A. M., Sharpe, D. M. T., Ghalambor, C. K., \& De Leon, L. F. (2018). Exploring the effects of salinization on trophic diversity in freshwater ecosystems: a quantitative review. Hydrobiologia, 807(1), 1-17. doi:10.1007/s10750-017-3403-0

Cézilly, F., Grégoire, A., \& Bertin, A. (2000). Conflict between co-occurring manipulative parasites? An experimental study of the joint influence of two acanthocephalan parasites on the behaviour of Gammarus pulex. Parasitology, 120(6), 625-630.

Cézilly, F., Favrat, A., \& Perrot-Minnot, M.-J. (2013). Multidimensionality in parasite-induced phenotypic alterations: ultimate versus proximate aspects. Journal of Experimental Biology, 216(1), 27-35. doi:10.1242/jeb.074005 
Fanton, H. et.al. (2020). Pomphorhynchus laevis manipulates Gammarus pulex behaviour despite salt pollution. Freshwater Biology. 2020; 65: 1718-1725. https://doi.org/10.1111/fwb.13573

Dezfuli, B. S., Maynard, B. J., \& Wellnitz, T. A. (2003). Activity levels and predator detection by amphipods infected with an acanthocephalan parasite, Pomphorhynchus laevis. Folia Parasitologica, 50(2), 129-134. doi:10.14411/fp.2003.023

Dorgelo, J. (1974). Comparative ecophysiology of gammarids (Crustacea: Amphipoda) from marine, brackish and fresh-water habitats, exposed to the influence of salinity-temperature combinations. Hydrobiological Bulletin, 8(1-2), 90-108.

Dray S., \& Dufour A. (2007). The ade4 Package: Implementing the Duality Diagram for Ecologists. Journal of Statistical Software, 22(4), 1-20. doi: 10.18637/jss.v022.i04.

Dunn, A. M., \& Hatcher, M. J. (1997). The effect of salinity on transovarial transmission of a microsporidian infecting Gammarus duebeni. Parasitology, 115, 381-385. doi:10.1017/s0031182097001492

Fox, J., \& Weisberg, S. (2018). Visualizing fit and lack of fit in complex regression models with predictor effect plots and partial residuals. Journal of Statistical Software, 87(9), 1-27. doi: 10.18637/jss.v087.i09, https://www.jstatsoft.org/v087/i09.

Galli, P., Mariniello, L., Crosa, G., Ortis, M., Ambrogi, A. O., \& D'Amelio, S. (1998). Populations of Acanthocephalus anguillae and Pomphorhynchus laevis in rivers with different pollution levels. Journal of Helminthology, 72(4), 331-335

Hengeveld, H. G. (1990). Global climate change: implications for air temperature and water supply in Canada. Transactions of the American Fisheries Society, 119(2), 176-182.

Herbert, E. R., Boon, P., Burgin, A. J., Neubauer, S. C., Franklin, R. B., Ardon, M., Gell, P. (2015). A global perspective on wetland salinization: ecological consequences of a growing threat to freshwater wetlands. Ecosphere, 6(10). doi:10.1890/es14-00534.1

Herczeg, A. L., Dogramaci, S. S., \& Leaney, F. W. J. (2001). Origin of dissolved salts in a large, semi-arid groundwater system: Murray Basin, Australia. Marine and Freshwater Research, 52(1), 41-52.

Hoback, W. W., \& Barnhart, M. C. (1996). Lethal limits and sublethal effects of hypoxia on the amphipod Gammarus pseudolimnaeus. Journal of the North American Benthological Society, 15(1), 117-126. doi:10.2307/1467437

Hudson, P. J., Dobson, A. P., \& Lafferty, K. D. (2006). Is a healthy ecosystem one that is rich in parasites? Trends in ecology \& evolution, 21(7), 381-385. doi:10.1016/j.tree.2006.04.007

Hume, K. D., Elwood, R. W., Dick, J. T., \& Morrison, J. (2005). Sexual dimorphism in amphipods: the role of male posterior gnathopods revealed in Gammarus pulex. Behavioral Ecology and Sociobiology, 58(3), 264-269. doi: 10.1007/s00265-005-0925-7

Kaldonski, N., Perrot-Minnot, M.-J., Dodet, R., Martinaud, G., \& Cézilly, F. (2008). Carotenoidbased colour of acanthocephalan cystacanths plays no role in host manipulation. Proceedings of the Royal Society B: Biological Sciences, 276(1654), 169-176. doi:10.1098/rspb.2008.0798

Kaushal, S. S., Likens, G. E., Pace, M. L., Utz, R. M., Haq, S., Gorman, J., \& Grese, M. (2018). Freshwater salinization syndrome on a continental scale. Proceedings of the National Academy of Sciences of the United States of America, 115(4). doi: 10.1073/pnas. 1711234115

Labaude, S., Cézilly, F., \& Rigaud, T. (2017a). Temperature-related intraspecific variability in the behavioral manipulation of acanthocephalan parasites on their gammarid hosts. The Biological Bulletin, 232(2), 82-90.

Labaude, S., Moret, Y., Cézilly, F., Reuland, C., \& Rigaud, T. (2017b). Variation in the immune state of Gammarus pulex (Crustacea, Amphipoda) according to temperature: Are extreme 
Fanton, H. et.al. (2020). Pomphorhynchus laevis manipulates Gammarus pulex behaviour despite salt pollution. Freshwater Biology. 2020; 65: 1718-1725. https://doi.org/10.1111/fwb.13573

temperatures a stress? Developmental \& Comparative Immunology, 76, 25-33. doi: 10.1016/j.dci.2017.05.013

Lafferty, K. D. (1997). Environmental parasitology: What can parasites tell us about human impacts on the environment? Parasitology Today, 13(7), 251-255. doi:10.1016/s01694758(97)01072-7

Lagrue, C., Kaldonski, N., Perrot-Minnot, M.-J., Motreuil, B., \& Bollache, L. (2007a). Modification of hosts' behavior by a parasite: Field evidence for adaptive manipulation. Ecology, 88(11), 2839-2847. doi:10.1890/06-2105.1

Lefèvre, T., Lebarbenchon, C., Gauthier-Clerc, M., Missé, D., Poulin, R., \& Thomas, F. (2009). The ecological significance of manipulative parasites. Trends in Ecology \& Evolution, 24(1), 41-48. doi:10.1016/j.tree.2008.08.007

Le Moullac, G., \& Haffner, P. (2000). Environmental factors affecting immune responses in Crustacea. Aquaculture, 191(1-3), 121-131.

Malmqvist, B., \& Rundle, S. (2002). Threats to the running water ecosystems of the world. Environmental Conservation, 29(2), 134-153. doi:10.1017/s0376892902000097

Marcogliese, D. J. (2008). The impact of climate change on the parasites and infectious diseases of aquatic animals. Revue Scientifique Et Technique-Office International Des Epizooties, 27(2), 467-484.

Maynard, B. J., Wellnitz, T. A., Zanini, N., Wright, W. G., \& Dezfuli, B. S. (1998). Parasitealtered behavior in a crustacean intermediate host: Field and laboratory studies. Journal of Parasitology, 84(6), 1102-1106. doi:10.2307/3284656

Mazerolle M. J. (2019) AICcmodavg: Model selection and multimodel inference based on (Q)AIC(c). R package version, $1,35$.

McCahon, C. P., Maund, S. J., \& Poulton, M. J. (1991). The effect of the Acanthocephalan parasite (Pomphorhynchus laevis) on the drift of its intermediate host (Gammarus pulex). Freshwater Biology, 25(3), 507-513. doi:10.1111/j.1365-2427.1991.tb01393.x

Médoc, V., Bollache, L., \& Beisel, J.-N. (2006). Host manipulation of a freshwater crustacean (Gammarus roeseli) by an acanthocephalan parasite (Polymorphus minutus) in a biological invasion context. International Journal for Parasitology, 36(13), 1351-1358. doi:10.1016/j.ijpara.2006.07.001

Paller, V. G. V., Resurreccion, D. B., de la Cruz, C. P. P., \& Bandal, M. Z. (2016). Acanthocephalan Parasites (Acanthogyrus sp.) of Nile Tilapia (Oreochromis niloticus) as Biosink of Lead $(\mathrm{Pb})$ Contamination in a Philippine Freshwater Lake. Bulletin of Environmental Contamination and Toxicology, 96(6), 810-815. doi:10.1007/s00128-0161790-y

Perrot-Minnot, M.-J. (2004). Larval morphology, genetic divergence, and contrasting levels of host manipulation between forms of Pomphorhynchus laevis (Acanthocephala). International journal for parasitology, 34(1), 45-54. doi:10.1016/j.ijpara.2003.10.005

Perrot-Minnot, M.-J., Maddaleno, M., Balourdet, A., \& Cézilly, F. (2012). Host manipulation revisited: no evidence for a causal link between altered photophobia and increased trophic transmission of amphipods infected with acanthocephalans. Functional Ecology, 26(5), 1007-1014. doi:10.1111/j.1365-2435.2012.02027.x

Perrot-Minnot, M. J., Sanchez-Thirion, K., \& Cézilly, F. (2014). Multidimensionality in host manipulation mimicked by serotonin injection. Proceedings of the Royal Society B: Biological Sciences, 281(1796), 20141915. doi: 10.1098/rspb.2014.1915

Pinheiro J., Bates D., Debroy S., Sarkar D., R Core Team (2019). nlme: Linear and Nonlinear Mixed Effects Models. $R$ package version, 3(0). 
Fanton, H. et.al. (2020). Pomphorhynchus laevis manipulates Gammarus pulex behaviour despite salt pollution. Freshwater Biology. 2020; 65: 1718-1725. https://doi.org/10.1111/fwb.13573

Piscart, C., Lecerf, A., Usseglio-Polatera, P., Moreteau, J. C., \& Beisel, J.-N. (2005). Biodiversity patterns along a salinity gradient: the case of net-spinning caddisflies. Biodiversity and Conservation, 14(9), 2235-2249. doi:10.1007/s10531-004-4783-9

Piscart, C., Moreteau, J. C., \& Beisel, J.-N. (2005). Biodiversity and structure of macroinvertebrate communities along a small permanent salinity gradient (Meurthe River, France). Hydrobiologia, 551, 227-236. doi:10.1007/s10750-005-4463-0

Piscart, C., Webb, D., \& Beisel, J.-N. (2007). An acanthocephalan parasite increases the salinity tolerance of the freshwater amphipod Gammarus roeseli (Crustacea: Gammaridae). Naturwissenschaften, 94(9), 741-747. doi:10.1007/s00114-007-0252-0

Piscart, C., Kefford, B. J., \& Beisel, J.-N. (2011). Are salinity tolerances of non-native macroinvertebrates in France an indicator of potential for their translocation in a new area? Limnologica, 41(2), 107-112.

Sanchez, M. I., Pons, I., Martinez-Haro, M., Taggart, M. A., Lenormand, T., \& Green, A. J. (2016). When parasites are good for health: Cestode parasitism increases resistance to arsenic in brine shrimps. PLoS Pathogens, 12(3). doi:e1005459

Sanchez-Thirion, K., Danger, M., Bec, A., Billoir, E., Labaude, S., Rigaud, T., Beisel, J.-N., \& Felten, V. (2019). High food quality increases infection of Gammarus pulex (Crustacea: Amphipoda) by the acanthocephalan parasite Pomphorhynchus laevis. International journal for parasitology, 49(10), 805-817. doi:10.1016/j.ijpara.2019.05.005

Sereda, J., Bogard, M., Hudson, J., Helps, D., \& Dessouki, T. (2011). Climate warming and the onset of salinization: rapid changes in the limnology of two northern plains lakes. Limnologica, 41(1), 1-9. doi:10.1016/j.limno.2010.03.002

Sornom, P., Felten, V., Médoc, V., Sroda, S., Rousselle, P., \& Beisel, J.-N. (2010). Effect of gender on physiological and behavioural responses of Gammarus roeseli (Crustacea Amphipoda) to salinity and temperature. Environmental Pollution, 158(5), 1288-1295. doi:10.1016/j.envpol.2010.01.022

Sures, B., Taraschewski, H., \& Jackwerth, E. (1994). Lead accumulation in Pomphorhynchus laevis and its host. Journal of Parasitology, 80(3), 355-357. doi:10.2307/3283403

Sures, B., Siddall, R., \& Taraschewski, H. (1999). Parasites as accumulation indicators of heavy metal pollution. Parasitology Today, 15(1), 16-21. doi:10.1016/s0169-4758(98)01358-1

Sures, B. (2008). Host-parasite interactions in polluted environments. Journal of Fish Biology, 73(9), 2133-2142. doi:10.1111/j.1095-8649.2008.02057.x

Sutcliffe, D. W., Carrick, T. R., \& Willoughby, L. G. (1981). Effects of diet, body size, age and temperature on growth-rates in the amphipod Gammarus pulex. Freshwater Biology, 11(2), 183-214. doi:10.1111/j.1365-2427.1981.tb01252.x

Taraschewski, H. (2000). Host-parasite interactions in acanthocephala: a morphological approach. Advances in Parasitology, Vol 46, 1-179. doi:10.1016/s0065-308x(00)46008-2

Velasco, J., Gutiérrez-Cánovas, C., Botella-Cruz, M., Sánchez-Fernández, D., Arribas, P., Carbonell, J. A., Millán, A., \& Pallarés, S. (2018). Effects of salinity changes on aquatic organisms in a multiple stressor context. Philosophical Transactions of the Royal Society B, 374(1764), 20180011. doi: 10.1098/rstb.2018.0011

Wijnhoven, S., van Riel, M. C., \& van der Velde, G. (2003). Exotic and indigenous freshwater gammarid species: physiological tolerance to water temperature in relation to ionic content of the water. Aquatic Ecology, 37(2), 151-158. doi:10.1023/a:1023982200529

Wickham, H. (2016) ggplot2: Elegant graphics for data analysis. Springer.

Williams, W. D. (2001). Anthropogenic salinisation of inland waters. Hydrobiologia, 466(1-3), 329-337. doi:10.1023/a:1014598509028 
Fanton, H. et.al. (2020). Pomphorhynchus laevis manipulates Gammarus pulex behaviour despite salt pollution. Freshwater Biology. 2020; 65: 1718-1725. https://doi.org/10.1111/fwb.13573

Xue, S. Y., Fang, J. G., Zhang, J. H., Jiang, Z. J., Mao, Y. Z., \& Zhao, F. Z. (2013). Effects of temperature and salinity on the development of the amphipod crustacean Eogammarus sinensis. Chinese Journal of Oceanology and Limnology, 31(5), 1010-1017. doi:10.1007/s00343-013-2302-0

Zganec, K., Gottsein, S., \& Hudina, S. (2013). Spatio-temporal variation of drift and upstream movements of the Amphipod Gammarus fossarum in a small unaltered stream. Polish Journal of Ecology, 61(4), 769-784

Zuur, A., Ieno, E. N., Walker, N., Saveliev, A. A., \& Smith, G. M. (2009). Mixed effects models and extensions in ecology with R. Springer Science \& Business Media. 
Fanton, H. et.al. (2020). Pomphorhynchus laevis manipulates Gammarus pulex behaviour despite salt pollution. Freshwater Biology. 2020; 65: 1718-1725. https://doi.org/10.1111/fwb.13573

\section{Supplementary material}

Table S1. Effects of the status (uninfected or P. laevis-infected G. pulex), salinity (control or saline water) and their interactions for the three behaviours observed (one column per model). The observed F-statistic values and their associated significance levels represented by stars $(* * *$ for $P<0.001$, ** for $P<0.01$, * for $P<0.05$, nothing if $P>0.05)$.

\begin{tabular}{lccc}
\hline Factor & Distance covered & Phototaxis & Geotaxis \\
\hline Status & $24.088 * * *$ & $69.367 * * *$ & $29.896 * * *$ \\
Salinity & $7.057 * *$ & $10.835 * *$ & $5.222 *$ \\
Status:Salinity & - & $5.924 *$ & - \\
\hline
\end{tabular}

